\title{
Influence of Temperature and Acid Etching Time on the Superficial Characteristics of Ti
}

\author{
Bruno Ramos Chrcanovic ${ }^{a *}$, Ann Wennerberg ${ }^{a}$, Maximiliano Delany Martins ${ }^{b}$ \\ ${ }^{a}$ Department of Prosthodontics, Faculty of Odontology, Malmö University, Carl Gustafs väg 34, \\ SE-205 06, Malmö, Sweden \\ ${ }^{b}$ Laboratório de Nanoscopia - LabNano, Centro de Desenvolvimento da Tecnologia Nuclear-CDTN, \\ Comissão Nacional de Energia Nuclear-CNEN, Av. Presidente Antônio Carlos, 6627, Campus da \\ UFMG, Pampulha, CEP 31270-901, Belo Horizonte, MG, Brazil
}

Received: May 4, 2015; Revised: July 28, 2015

\begin{abstract}
We evaluated the influence of the etching time and temperature of an acid solution $\left(\mathrm{HCl} / \mathrm{H}_{2} \mathrm{SO}_{4}\right)$ on the chemical and topographical superficial characteristics of cpTi grade IV. Samples were analyzed by electron microscopy, interferometry, and grazing incidence XRD. The surfaces kept the irregularity aspect when submitted to the same etching temperature. On the other hand, the irregularities increased in size and depth with increasing etching time. The etching treatments that produced higher values for roughness parameters showed a combination of high temperature for a longer etching time. Some treatments produced very large irregularities, with a brittle surface in some regions. According to statistical correlation, the temperature made the strongest contribution in the variance of the mean values of the surface roughness parameters when compared to the etching time. Titanium and oxygen were the only elements on the surface in all groups. All test group samples showed the presence of titanium hydride.
\end{abstract}

Keywords: titanium, surface modification, acid-etching, temperature, surface characterization

\section{Introduction}

For more than 30 years now, surface structure has been identified as one of six factors particularly important for implant incorporation in bone ${ }^{1}$. Alterations in endosseous dental implant surface have been revisited extensively to decrease treatment time frames by reducing the healing period for osseointegration establishment ${ }^{2,3}$. An increasing number of surface modification techniques have been introduced, and the etching of titanium by acids is one of them.

Acid etching is a subtractive method, wherein pits are created in the titanium surface ${ }^{4}$. The technique is of particular interest because it creates a microtextured surface (fine rough surface with micro pits of 1-3 $\mu \mathrm{m}$ and larger pits of approximately 6-10 $\mu \mathrm{m}$ ) that appears to enhance early endosseous integration and stability of the implant ${ }^{5}$. The method may have advantages compared with some other methods of roughening such as grit blasting, plasma spraying, and beads. As the process does not stress the adjacent material, there is no risk of flaking or delamination, thus leaving particles of grit ${ }^{6-8}$.

It has been suggested that the surface modification of titanium by acid etching has a positive effect on endosseous integration. In the study of Lazzara et al. ${ }^{9}$, the bone response to the Osseotite implant (it has a turned and dual acid-etched surface by $\mathrm{HCl} / \mathrm{H}_{2} \mathrm{SO}_{4}$ ) was compared to implants with turned surfaces, both placed in the human posterior maxilla. The bone contact at the acid-etched surface was significantly higher after 6 months of healing when compared to the turned surfaces, and the osteoconductive effect, i.e. the amount of

*e-mail: bruno.chrcanovic@mah.se, brunochrcanovic@hotmail.com bone apposition, of the acid-etched surface over the turned was particularly pronounced in the softer trabecular bone. In a study conducted in a rabbit tibia model, Klokkevold et al. ${ }^{5}$ compared the anchorage of acid-etched (by $\mathrm{HCl} / \mathrm{H}_{2} \mathrm{SO}_{4}$ ) and turned surfaces and observed a statistically significant higher mean removal torque for the acid-etched surface after 1,2, and 3 months. He et al. ${ }^{10}$, treating titanium by $\mathrm{HF} / \mathrm{HNO}_{3}$, and Zareidoost et al. ${ }^{11}$, treating titanium by $\mathrm{HCl}, \mathrm{HF}$, and $\mathrm{H}_{3} \mathrm{PO}_{4}$, showed that acid-etched titanium surfaces had lower cytotoxicity level, better biocompatibility, and higher roughness than the control samples not submitted to etching. On the other hand, etching does not always increase the surface roughness, as described by Albrektsson \& Wennerberg ${ }^{12}$. Etched commercial available implants may have a roughness comparable to turned Brånemark implants, i.e. a $\mathrm{S}_{\mathrm{a}}$ value of approximately $0.5 \mu \mathrm{m}$ but with a change from an anisotropic to an isotropic surface due to the removal of cut marks from the machining technique by the etching procedure.

It is possible to control and vary selected surface properties of titanium over a relatively wide range using different surface preparation methods. Understanding how these methods influence the surface properties is important, as these may increase the biological response to dental implants, and consequently influence its success rates. As the surface chemistry and topography obtained by acid etching can be modulated according to variations in the treatment, the aim of the present study was to evaluate the influence of temperature and etching time of an acid solution of $\mathrm{HCl} / \mathrm{H}_{2} \mathrm{SO}_{4}$ on the chemical and topographical superficial characteristics of cpTi grade IV. 


\section{Material and Methods}

\subsection{Materials}

Thirty machined cpTi grade IV discs $(12.7 \times 2.0 \mathrm{~mm})$ were used as the substrate material for the experiment. All discs were cut from a rod using a IsoMet ${ }^{\circledR}$ Low Speed Saw (Buehler ${ }^{\circledR}$, Lake Bluff, USA) with a Diamond Wafering Blade No. 11-4244 (diameter 4"-102mm / thickness 0.012"-0.3mm) from the same manufacturer. The samples were mounted in polymethyl methacrylate resin, in order to be polished in a polishing machine until a \#2000 silicon carbide paper.

The discs were separated into a control group and 9 test groups. Each group had 3 discs. Each test group was acid-etched with a solution of $\mathrm{HCl} / \mathrm{H}_{2} \mathrm{SO}_{4}$ and classified into different groups depending on the temperature and etching time, as follows: AT1 $\left(60^{\circ} \mathrm{C}, 5 \mathrm{~min}\right), \mathrm{AT} 2\left(60^{\circ} \mathrm{C}, 15 \mathrm{~min}\right)$, AT3 $\left(60{ }^{\circ} \mathrm{C}, 30 \mathrm{~min}\right)$, AT4 $\left(90^{\circ} \mathrm{C}, 5 \mathrm{~min}\right)$, AT5 $\left(90^{\circ} \mathrm{C}\right.$, $15 \mathrm{~min})$, AT6 $\left(90^{\circ} \mathrm{C}, 30 \mathrm{~min}\right)$, AT7 $\left(120^{\circ} \mathrm{C}, 5 \mathrm{~min}\right)$, AT8 $\left(120^{\circ} \mathrm{C}, 15 \mathrm{~min}\right)$, and $\mathrm{AT} 9\left(120^{\circ} \mathrm{C}, 30 \mathrm{~min}\right)$.

\subsection{Characterization}

The surface morphology of the samples was examined by scanning electron microscopy (SEM - JEOL, model JSM-5310, Tokyo, Japan). The secondary electron (SE) detection mode with an acceleration voltage of $25 \mathrm{kV}$ was selected for SEM analysis and the vacuum pressure was maintained below $1 \times 10^{-5}$ Torr. The load current (LC) was approximately $85 \mu \mathrm{A}$. For a direct comparison of the surface morphology, the same magnification of $1000 \mathrm{x}$ was selected for all samples.

In order to obtain quantitative analysis of the surface roughness, the samples were examined by interferometry using a MicroXAM instrument (ADE Phase shift Technology, Inc., Tuczon, USA). The analysis was performed at ten random sites of the samples surface, with a scanning area of $200 \mu \mathrm{m} \times 260 \mu \mathrm{m}$. Surfascan software version 4.2.4.1 (Hommel-Etamic GmbH, Villingen-Schwenningen, Germany) was used to calculate the topographical parameters. Three distinct roughness parameters were reported for each surface, according to a suggested guideline ${ }^{13}: \mathrm{S}_{\mathrm{a}}(\mu \mathrm{m})=$ average height deviation from a mean plane, $\mathrm{S}_{\mathrm{ds}}\left(\mu \mathrm{m}^{-2}\right)=$ density of summits and $\mathrm{S}_{\mathrm{dr}}(\%)=$ developed surface ratio.

The parameters are defined ${ }^{14}$ as follows:

(a) $\mathrm{S}_{\mathrm{a}}$ (arithmetic mean deviation of the surface). It is a parameter for characterizing the amplitude property of surfaces. It is a dispersion parameter defined as the arithmetic mean of the absolute values of the surface departures above and below the mean plane within the sampling area. It is given by the formula

$$
S_{a}=\frac{1}{M N} \sum_{j=1}^{N} \sum_{i=1}^{M}\left|z_{i j}-\bar{z}\right|
$$

(b) $\mathrm{S}_{\mathrm{ds}}$ (density of summits of the surface). It is a parameter for characterizing the spatial property of surfaces. This is the number of summits of a unit sampling area. It is given by the formula

$S_{d s}=\frac{\text { Number of summits }}{(M-1)(N-1) \cdot \Delta x \cdot \Delta y}$ (c) $\mathrm{S}_{\mathrm{dr}}$ (developed interfacial area ratio). It is a parameter for characterizing the hybrid property of surfaces. The hybrid property is a combination of amplitude and spacing. Any changes which occur in either amplitude or spacing may have an effect on the hybrid property. This is the ratio of the increment of the interfacial area of a surface over the sampling area. A large value of the parameter indicates the significance of either the amplitude or the spacing or both. It is given by the formula

$$
S_{d r}=\frac{\sum_{j=1}^{N-1} \sum_{i=1}^{M-1} A_{i j}-(M-1)(N-1) \cdot \Delta x \cdot \Delta y}{(M-1)(N-1) \cdot \Delta x \cdot \Delta y} .100 \%
$$

Before the parametrical calculation could be evaluated, the waviness from the surface was removed using a $50 \times 50 \mu \mathrm{m}$ Gaussian filter. A statistical analysis of the values of the surface roughness parameters and their relation with the temperature and etching time were composed and compared with One-Way Analysis of Variance (ANOVA) or Kruskal Wallis test, where indicated, depending on the normality (Kolmogorov-Smirnov test). When ANOVA was indicated, the Tukey's HSD test was also performed, in order to find means that are significantly different from each other. Pearson correlation and linear regression were also performed in order to verify the relationship between the surface roughness parameters and the temperature, and between the surface roughness parameters and the etching time. Standard multiple regression was performed in order to verify the relationship between the surface roughness parameters and the two predictors at the same time. The degree of statistical significance was considered $P<0.05$. The Statistical Package for the Social Sciences (SPSS) software version 20 (SPSS Inc., Chicago, USA) was used to perform the statistical analysis.

The surface chemical composition was analyzed by energy dispersive $\mathrm{x}$-ray spectroscopy (EDS - JEOL, model JXA-8900RJ, Tokyo, Japan). The most central region of the samples was chosen, and the analysis was made with a magnification of 200x. The elemental chemical composition was calculated by the mean value and standard deviation from the 3 samples of each group.

Moreover, grazing incidence X-ray diffraction (GIXRD) measurements were carried out in a Ultima IV X-ray diffractometer (Rigaku, Tokyo, Japan), using $\mathrm{Cu}-\mathrm{K}_{\alpha 1}$ radiation at $30 \mathrm{kV}$ and tube current of $20 \mathrm{~mA}$, without any filter or monochromator, in the angle range of $10^{\circ}-90^{\circ}(2 \theta)$ with a grazing incidence of $3^{\circ}$, making the diffraction sensitive to the surface. The step of measurement was set to $0.05^{\circ}$ with a scan rate of $0.5^{\circ}$ per minute. The divergence slit was set to $1 \mathrm{~mm}$, with a Div H.L. Slit of $2 \mathrm{~mm}$. The results were analyzed in Search-Match software (Crystallographica, Oxford, United Kingdom). GIXRD experiments were carried out in order to distinguish chemical compounds at the sample surface.

\section{Results}

\subsection{SEM analysis}

Figures $1 \mathrm{a}$ to $1 \mathrm{j}$ revealed characteristic differences at the microscopic level according to the surface modification methods used for the samples as measured by SEM. Differences of the 


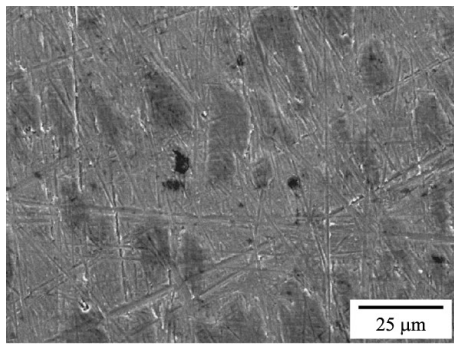

(a)

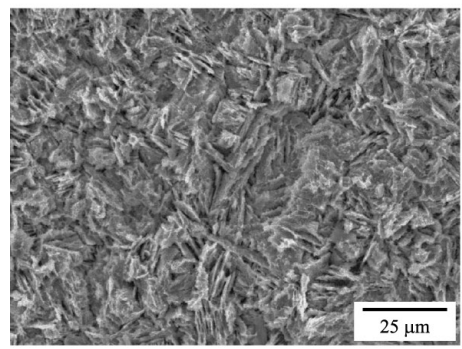

(d)

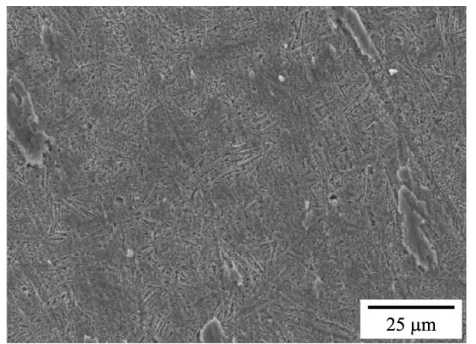

(b)

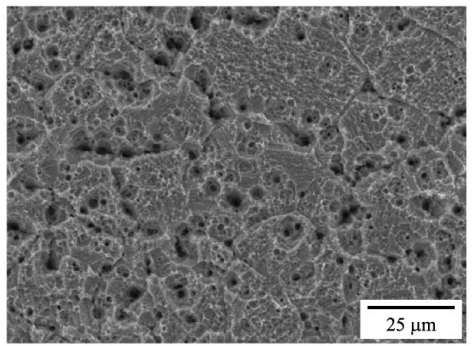

(e)

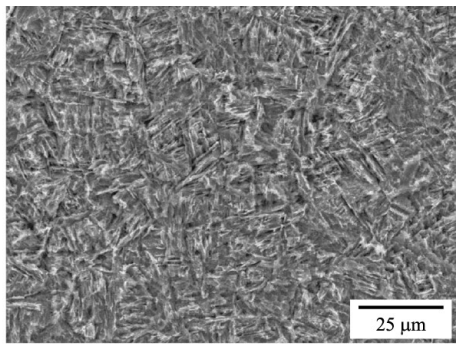

(c)

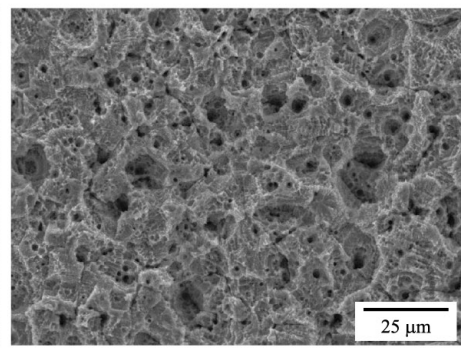

(f)

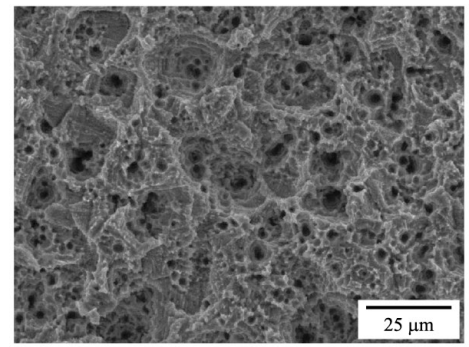

(g)

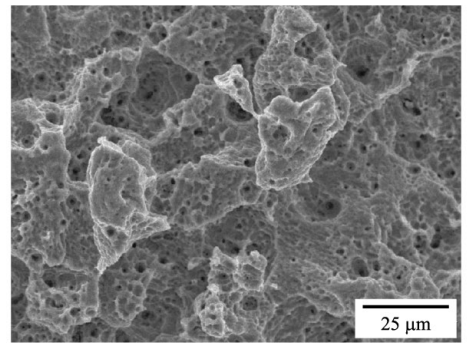

(i)

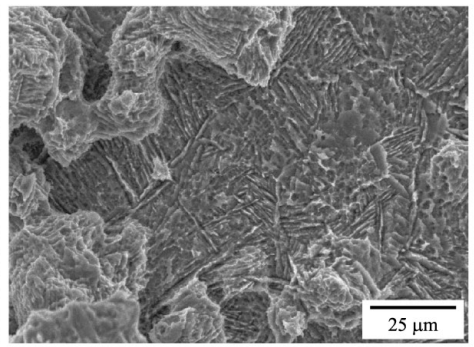

(h)

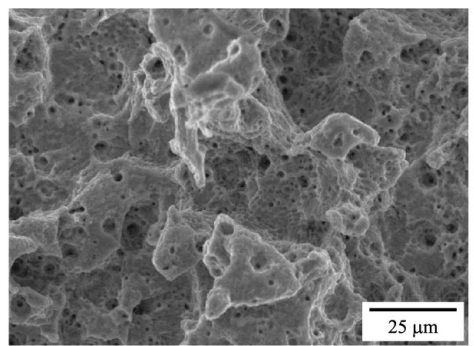

(j)

Figure 1. SEM pictures of control group (a), AT1 (b), AT2 (c), AT3 (d), AT4 (e), AT5 (f), AT6 (g), AT7 (h), AT8 (i), and AT9 groups (j) (original magnification 1000x - scale bar $25 \mu \mathrm{m}$ ).

surfaces were obvious between the groups due to differences of the etching processes. The control group samples were mainly characterized by multidirectional grooves as result of the polishing process (Figure 1a). Samples submitted to acid treatment under $60{ }^{\circ} \mathrm{C}$ (AT1, AT2, AT3; Figures 1b, 1c, 1d, respectively) showed a homogenous distribution of linear irregularities with grooves and sharp edges throughout the surface. The irregularities increased in size with the increasing etching time. The sample group AT1 showed some small unetched regions, probably due to the short period of etching ( 5 minutes, Figure 1b). The groups that were etched under $90{ }^{\circ} \mathrm{C}$ (AT4, AT5, AT6; Figures 1e, 1f, 1g, respectively) showed several micro-pits on the surface, increasing in size and in depth with the increase of the etching time. Finally, from the groups that were etched under $120^{\circ} \mathrm{C}$, the group AT7 (Figure 1h) showed a surface with some deep valleys and some areas of relatively plain surface, while AT8 (Figure 1i) and AT9 (Figure 1j) demonstrated more irregular surfaces, with larger and deeper valleys and peaks with micro-pits throughout the surface. When seen by the naked eye, the samples from the groups AT8 $\left(120{ }^{\circ} \mathrm{C} 15 \mathrm{~min}\right)$ and AT9 $\left(120^{\circ} \mathrm{C} 30 \mathrm{~min}\right)$ produced very large irregularities with a brittle surface that peeled out in some regions when scratched.

\subsection{Interferometry analysis}

The qualitative and quantitative surface topography demonstrated different degrees of roughness. The topographic maps obtained by interferometry showed, qualitatively, the 
difference in roughness between the ten surfaces: control group (Figure 2a) and test groups AT1 to AT9 (Figures 2b-j, respectively).

Table 1 shows the mean values of three-dimensional roughness parameters for the sample groups separated by groups of same temperature, as determined by interferometry. It can be observed that the surfaces of the samples from control group showed smaller mean values of the roughness parameters than the test groups. Comparison of the mean values of the surface roughness parameters with ANOVA showed that the difference of the values between the groups revealed to be statistically significant for all parameters, except for $\mathrm{S}_{\mathrm{ds}}$ from the samples treated at the temperature of $90^{\circ} \mathrm{C}$. The mean values of $\mathrm{S}_{\mathrm{a}}$ and $\mathrm{S}_{\mathrm{dr}}$ tended to increase with the increase of etching time and temperature, while the mean value of $\mathrm{S}_{\mathrm{ds}}$ tended to decrease with the increase of etching time and temperature.

When Pearson correlation and linear regression were performed to verify the relationship between the surface roughness parameters and the temperature (Table 2), it was observed that $43.2 \%$ of the variance in $\mathrm{S}_{\mathrm{a}}$ is being explained by the temperature. Presenting $p=0.000$ for both coefficients, shows that the model fits very well the data. The numbers for $\mathrm{S}_{\mathrm{dr}}$ and $\mathrm{S}_{\mathrm{ds}}$ were $34.6 \%$ and $31.3 \%$, respectively, with their both coefficients also presenting $p=0.000$. According with the statistical models, for every $1{ }^{\circ} \mathrm{C}$ increase in the temperature, there is an increase of $0.064 \mu \mathrm{m}$ in $\mathrm{S}_{\mathrm{a}}$, an increase of $4.4 \%$ in $\mathrm{S}_{\mathrm{dr}}$, and a decrease of $654 \mu \mathrm{m}^{-2}$ in $\mathrm{S}_{\mathrm{ds}}$.

When Pearson correlation and linear regression were performed to verify the relationship between the surface roughness parameters and the etching time (Table 3 ), it

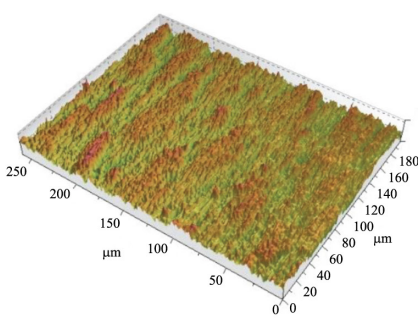

(a)

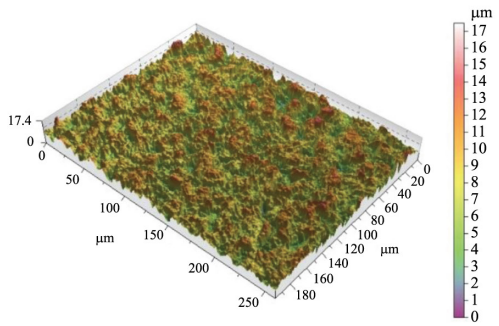

(d)
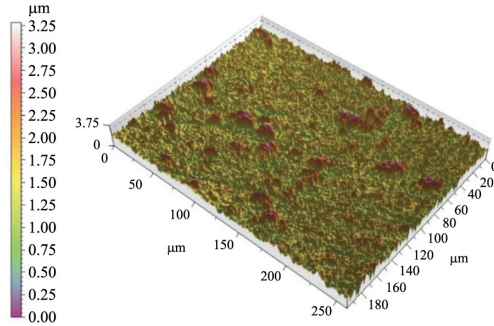

(b)

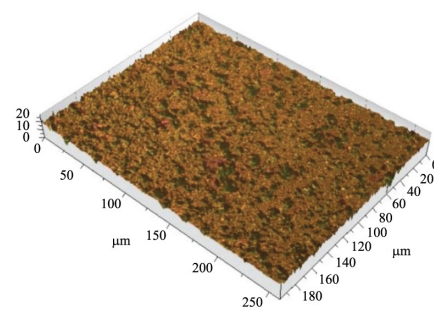

(e)
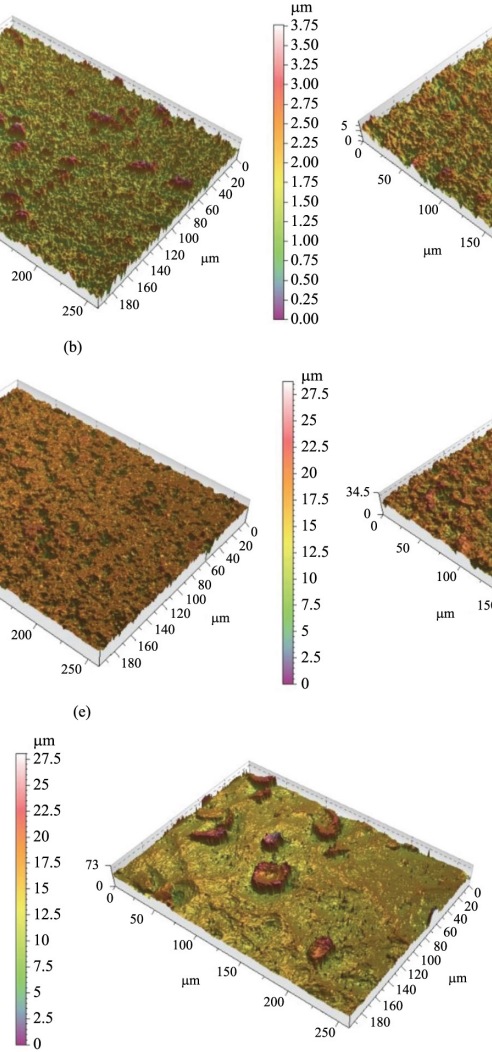

(h)
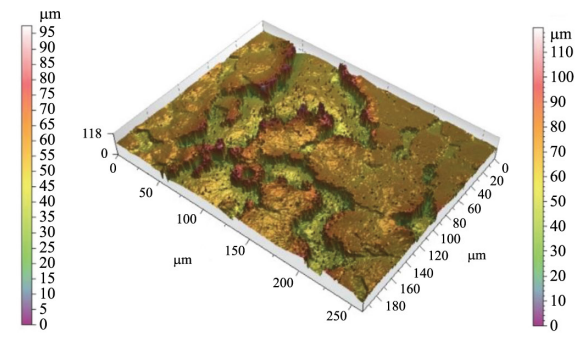

(j)
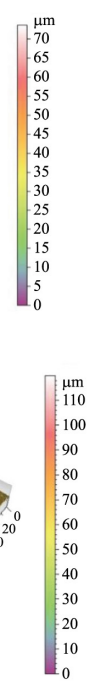

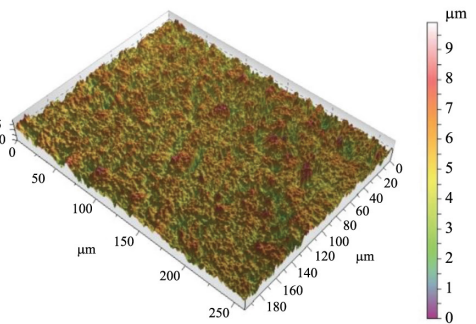

(c)

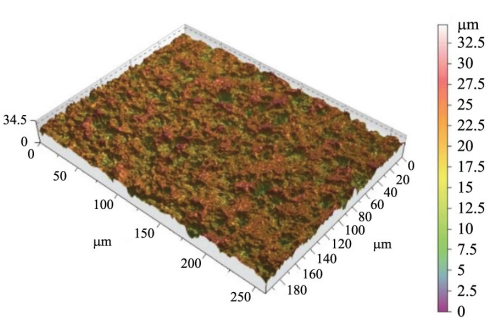

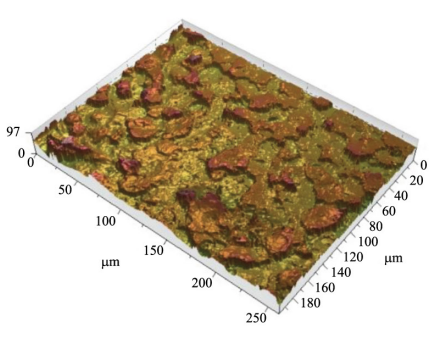

(i)

Figure 2. Interferometry topography maps for the control group (a), AT1 (b), AT2 (c), AT3 (d), AT4 (e), AT5 (f), AT6 (g), AT7 (h), AT8 (i), and AT9 groups (j) (scanning area: $200 \mu \mathrm{m} \times 260 \mu \mathrm{m})$. 
Table 1. Mean values $( \pm \mathrm{SD})$ of the three-dimensional roughness parameters of the samples separated by groups of same temperature, as determined by interferometry (scanning area of $200 \mu \mathrm{m} \times 260 \mu \mathrm{m}$ ), and $p$-values for one-way ANOVA comparisons.

\begin{tabular}{|c|c|c|c|}
\hline Group & $\mathrm{S}_{\mathrm{a}}(\mu \mathrm{m})$ & $S_{d r}(\%)$ & $\mathrm{S}_{\mathrm{ds}}\left(\mu \mathrm{m}^{-2}\right)$ \\
\hline \multirow[t]{2}{*}{ Control } & $0.275 \pm 0.034$ & $6.3 \pm 1.5$ & $128938 \pm 9184$ \\
\hline & \multicolumn{3}{|c|}{ Temperature $60^{\circ} \mathrm{C}$} \\
\hline AT1 (5 min) & $0.518 \pm 0.282^{a}$ & $34.9 \pm 20.9^{\mathrm{a}}$ & $221262 \pm 24576^{\mathrm{a}, \mathrm{b}, \mathrm{c}}$ \\
\hline AT2 (15 min) & $1.067 \pm 0.551^{\mathrm{a}}$ & $63.2 \pm 28.8^{\text {a }}$ & $208891 \pm 14510^{\mathrm{a}, \mathrm{c}}$ \\
\hline AT3 (30 min) & $1.510 \pm 0.306^{\mathrm{a}, \mathrm{c}}$ & $87.6 \pm 24.1^{a}$ & $207126 \pm 17793^{b, c}$ \\
\hline \multirow{2}{*}{$p$-value } & $<0.001$ & $<0.001$ & 0.011 \\
\hline & \multicolumn{3}{|c|}{ Temperature $90^{\circ} \mathrm{C}$} \\
\hline AT4 (5 min) & $0.832 \pm 0.307^{\mathrm{a}, \mathrm{b}}$ & $49.1 \pm 17.7^{\text {a }}$ & $194404 \pm 19415^{c}$ \\
\hline AT5 (15 min) & $2.017 \pm 0.915^{\mathrm{a}, \mathrm{c}}$ & $99.0 \pm 38.0 \mathrm{a}$ ac & $188516 \pm 32480^{c}$ \\
\hline AT6 (30 min) & $2.381 \pm 0.663^{\mathrm{b}, \mathrm{c}}$ & $138.3 \pm 36.3^{\mathrm{a}, \mathrm{c}}$ & $201927 \pm 23019^{c}$ \\
\hline \multirow[t]{2}{*}{$p$-value } & $<0.001$ & $<0.001$ & 0.132 \\
\hline & \multicolumn{3}{|c|}{ Temperature $120^{\circ} \mathrm{C}$} \\
\hline AT7 (5 min) & $2.547 \pm 1.273^{a, b, c}$ & $142.4 \pm 92.3^{a, b, c}$ & $186831 \pm 16759^{a, c}$ \\
\hline AT8 (15 min) & $5.836 \pm 2.454^{\mathrm{a}, \mathrm{c}}$ & $376.5 \pm 198.8^{\mathrm{a}, \mathrm{c}}$ & $159629 \pm 23477^{\mathrm{a}, \mathrm{c}}$ \\
\hline AT9 (30 min) & $6.247 \pm 2.690^{\mathrm{b}, \mathrm{c}}$ & $462.1 \pm 266.5^{\mathrm{b}, \mathrm{c}}$ & $172987 \pm 26681^{\mathrm{c}}$ \\
\hline$p$-value & $<0.001$ & $<0.001$ & $<0.001$ \\
\hline \multicolumn{4}{|c|}{ 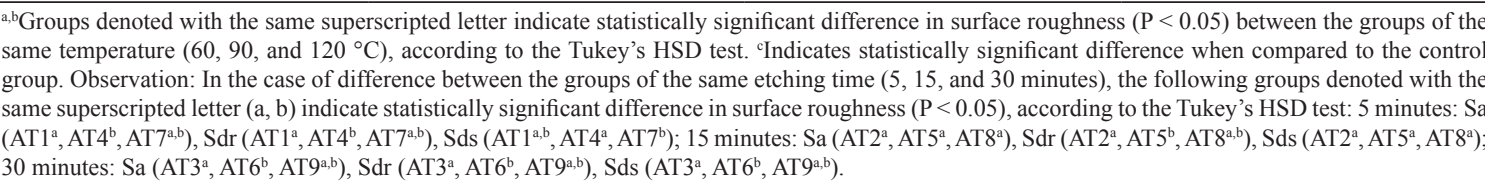 } \\
\hline
\end{tabular}

Table 2. Pearson correlation and linear regression results of the relationship between the surface roughness parameters and the temperature.

\begin{tabular}{|c|c|c|c|c|c|c|}
\hline \multirow{2}{*}{$\begin{array}{l}\text { Roughness } \\
\text { parameter }\end{array}$} & \multicolumn{3}{|c|}{ Temperature } & \multirow{2}{*}{$\begin{array}{c}\text { Correlation } \\
\text { (Pearson) }\end{array}$} & \multirow{2}{*}{ Equation } & \multirow{2}{*}{ Standard Error } \\
\hline & $\mathbf{R}$ & $\mathbf{R}^{2}$ & $p$-value & & & \\
\hline $\mathrm{S}_{\mathrm{a}}$ & 0.657 & 0.432 & $<0.001$ & Strong & $y=-3.217+0.064 x$ & 1.806 \\
\hline $\mathrm{S}_{\mathrm{dr}}$ & 0.588 & 0.346 & $<0.001$ & Moderate & $y=-236.2+4.4 x$ & 149.5 \\
\hline $\mathrm{S}_{\mathrm{ds}}$ & -0.560 & 0.313 & $<0.001$ & Moderate & $y=252424-654 x$ & 23825 \\
\hline
\end{tabular}

was observed that $11.5 \%$ of the variance in $\mathrm{S}_{\mathrm{a}}$ is being explained by the etching time. Presenting $p=0.000$ for both coefficients, shows that the model fits very well the data. The numbers for $\mathrm{S}_{\mathrm{dr}}$ and $\mathrm{S}_{\mathrm{ds}}$ were $10.9 \%$ and $0.06 \%$, respectively, with their coefficients presenting $p=0.002$ for the coefficient ' $\mathrm{a}$ ' and $p=0.000$ for the coefficient ' $\mathrm{b}$ ', and $p=0.000$ for the coefficient ' $\mathrm{a}$ ' and $p=0.223$ for the coefficient ' $b$ ', respectively. In this case, the ' $b$ ' coefficient is not making a statistically significant unique contribution to the outcome at the statistical model for $\mathrm{S}_{\mathrm{ds}}$, because of the lack of significance of it. According to the statistical models, for every 1 minute increase in the etching time, there is an increase of $0.079 \mu \mathrm{m}$ in $\mathrm{S}_{\mathrm{a}}$, an increase of $5.9 \%$ in $\mathrm{S}_{\mathrm{dr}}$, and a decrease of $207 \mu \mathrm{m}^{-2}$ in $\mathrm{S}_{\mathrm{d}}$.

An explanation is required in order to better understand the meaning of the coefficients. The linear regression analysis provides coefficients for the predictor variables, the regression coefficients. The linear regression is an approach for modeling the relationship between a scalar dependent variable ' $y$ ' and one or more explanatory variables (or independent variable) denoted ' $x$ '. When there is only one explanatory variable (in this case, the etching time), only a first degree equation $(y=a+b x)$ is possible. The ' $b$ ' coefficient in this case suggests how much the value of the roughness parameters will increase for every 1 minute increase in the etching time. As the ' $b$ ' coefficient for the $\mathrm{S}_{\mathrm{ds}}$ model was not statistically significant, it can be said that there is no significant effect of the etching time on the variance of the value of $\mathrm{S}_{\mathrm{ds}}$.

From the results presented at the Tables 3 and 4, it can be observed that the temperature has a stronger influence on the outcome (variation in the value of the roughness parameters) than the etching time.

The results for the standard multiple regression are summarized in Table 4. As the standardized coefficient for the first independent variable $(0.657,0.588,-0.560$, for $\mathrm{S}_{\mathrm{a}}, \mathrm{S}_{\mathrm{dr}}$, and $\mathrm{S}_{\mathrm{ds}}$, respectively) was larger than standardized coefficient for the second independent variable $(0.339,0.331$, -0.074 , for $\mathrm{S}_{\mathrm{a}}, \mathrm{S}_{\mathrm{dr}}$, and $\mathrm{S}_{\mathrm{ds}}$, respectively) for all parameters, the temperature makes the strongest contribution in explaining the outcome than the etching time. According to the model, $54.7 \%$ of the variance in the $\mathrm{S}_{\mathrm{a}}$ value is explained by the model, while $45.3 \%$ is explained by other factors. The values are $45.5 \%$ and $54.5 \%$, and $31.9 \%$ and $68.1 \%$, for $\mathrm{S}_{\mathrm{dr}}$ and $\mathrm{S}_{\mathrm{ds}}$, respectively. The three models have a $p=0.000$, meaning that they are very good predictor of the outcome. Concerning all the coefficients of all three models, only the coefficient for 
Table 3. Pearson correlation and linear regression results of the relationship between the surface roughness parameters and the etching time.

\begin{tabular}{|c|c|c|c|c|c|c|}
\hline \multirow{2}{*}{$\begin{array}{l}\text { Roughness } \\
\text { parameter }\end{array}$} & \multicolumn{3}{|c|}{ Etching time } & \multirow{2}{*}{$\begin{array}{c}\text { Correlation } \\
\text { (Pearson) }\end{array}$} & \multirow{2}{*}{ Equation } & \multirow{2}{*}{ Standard Error } \\
\hline & $\mathbf{R}$ & $\mathbf{R}^{2}$ & $p$-value & & & \\
\hline $\mathrm{S}_{\mathrm{a}}$ & 0.339 & 0.115 & $<0.001$ & Weak & $\mathrm{y}=1.238+0.079 x$ & 2.255 \\
\hline $\mathrm{S}_{\mathrm{dr}}^{\mathrm{a}}$ & 0.331 & 0.109 & $<0.001$ & Weak & $y=62.6+5.9 x$ & 174.4 \\
\hline $\mathrm{S}_{\mathrm{ds}}$ & -0.074 & 0.006 & 0.223 & Very Weak & $y=196964-207 x$ & 28672 \\
\hline
\end{tabular}

Table 4. Standard multiple regression results of the relationship between the surface roughness parameters and the two predictors.

\begin{tabular}{|c|c|c|c|c|c|c|c|}
\hline \multirow{2}{*}{$\begin{array}{l}\text { Roughness } \\
\text { parameter }\end{array}$} & \multicolumn{3}{|c|}{ Temperature + Etching time } & \multirow{2}{*}{ Equation } & \multirow{2}{*}{$\begin{array}{c}\text { Standard } \\
\text { Error }\end{array}$} & \multicolumn{2}{|c|}{ Collinearity } \\
\hline & $\mathbf{R}$ & $\mathbf{R}^{2}$ & $p$-value & & & Tolerance & VIF \\
\hline $\mathrm{S}_{\mathrm{a}}$ & 0.740 & 0.547 & $<0.001$ & $\mathrm{y}=-4.530+0.064 \mathrm{x}_{1}+0.079 \mathrm{x}_{2}$ & 1.616 & $1.000^{\mathrm{a}}$ & $1.000^{\mathrm{a}}$ \\
\hline $\mathrm{S}_{\mathrm{dr}}$ & 0.675 & 0.455 & $<0.001$ & $y=-335.0+4.4 x_{1}+5.9 x_{2}$ & 136.7 & $1.000^{\mathrm{a}}$ & $1.000^{\mathrm{a}}$ \\
\hline $\mathrm{S}_{\mathrm{ds}}$ & 0.565 & 0.319 & $<0.001$ & $\mathrm{y}=255880-654 \mathrm{x}_{1}-207 \mathrm{x}_{2}$ & 23773 & $1.000^{\mathrm{a}}$ & $1.000^{\mathrm{a}}$ \\
\hline
\end{tabular}

VIF - variance inflation factor. ${ }^{\text {a }}$ The same value for both 'b' coefficients.

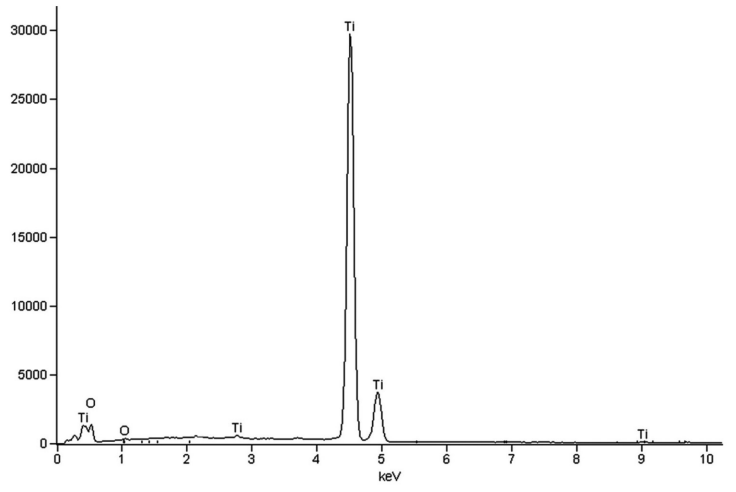

Figure 3. Typical EDS spectrum of a sample from group AT2, showing oxygen $(\mathrm{O})$ and titanium $(\mathrm{Ti})$ peaks.

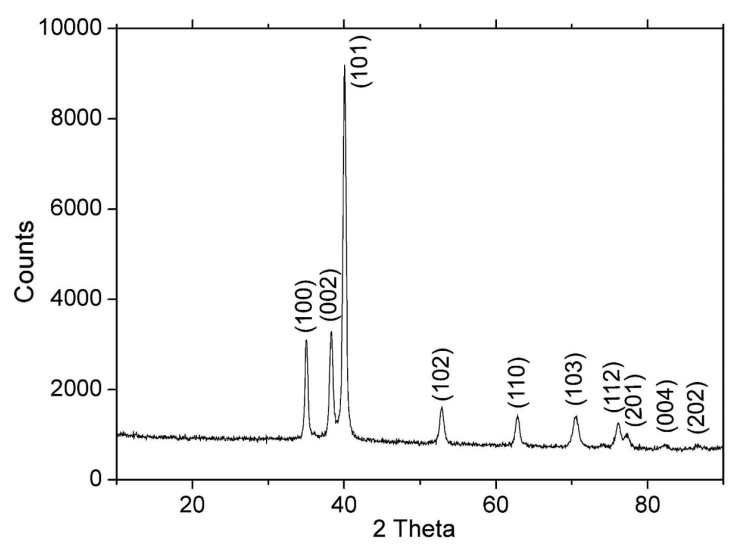

Figure 4. Typical GIXRD diffractogram for the control group sample, showing peak identification (Miller indices). See text for details.

etching time at the $\mathrm{S}_{\mathrm{ds}}$ model was not statistically significant ( $p=0.142)$, meaning that this one is not making a statistically significant unique contribution to the outcome.

The collinearity diagnosis related to the ' $b$ ' coefficients showed that the values of tolerance and variance inflation factor (VIF) do not suggest multicollinearity in any of the

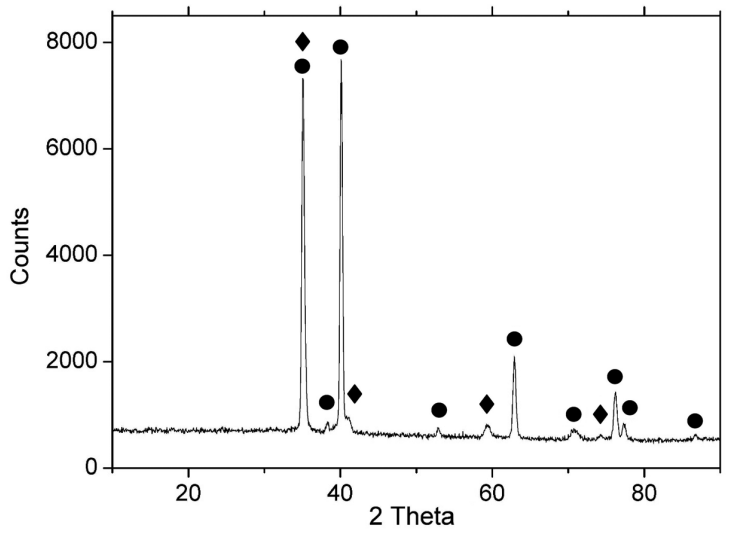

Figure 5. A typical GIXRD diffractogram of the acid-etched samples. Peak identification according to crystal structures: Ti (circle), $\mathrm{TiH}_{2}$ (diamond)

three models (for $\mathrm{S}_{\mathrm{a}}, \mathrm{S}_{\mathrm{dr}}$, and $\mathrm{S}_{\mathrm{ds}}$ ). Thus, the independent variables (temperature and etching time) are not highly correlated to each other in this particular data set, so then there is no imprecise estimate of the effect of independent changes in the independent variables ( $\mathrm{x}_{1}$ and $\mathrm{x}_{2}$, respectively).

\subsection{EDS analysis}

EDS analysis of the surfaces showed titanium and oxygen to be the only elements in all groups, with an average \% atomic concentration of $60 \%$ and $40 \%$, respectively. Figure 3 shows a typical EDS spectrum of the test groups.

\subsection{XRD analysis}

Figure 4 presents a typical GIXRD diffractogram for a sample from the control group, where diffraction peaks were labeled according to Miller indices, as described elsewhere ${ }^{15}$. The diffractogram analysis confirmed the presence of titanium (Ti) only. The GIXRD results obtained for the samples from groups submitted to acid etching showed the presence of $\mathrm{Ti}$ and titanium hydride $\left(\mathrm{TiH}_{2}\right)$ in all test groups (Figure 5). 


\section{Discussion}

The present study evaluated the influence of temperature and etching time of an acid solution of $\mathrm{HCl} / \mathrm{H}_{2} \mathrm{SO}_{4}$ on the chemical and topographical superficial characteristics of cpTi grade IV. Due to the distinct treatment parameters, every surface displayed distinct surface roughness characteristics. As the etching temperature was raised, surface irregularities became deeper, and the mean $\mathrm{S}_{\mathrm{a}}$ and $\mathrm{S}_{\mathrm{dr}}$ increased. Some studies have demonstrated that increases in the numerical surface roughness of an implant enhance biomechanical anchorage in bone, as determined by torque removal tests ${ }^{16}$ and resistance to push-out forces ${ }^{17}$. These studies showed a tendency toward an increase in bone contact, and resistance to removal, with an increasing numerical implant surface roughness. Specific to dental implants, studies have shown that histologic and biomechanical characteristics were improved due to increase in the as-machined surface texture by varied methods resulting in average implant surface roughness $\left(\mathrm{S}_{\mathrm{a}}\right)$ ranging from 0.5 to $2 \mu \mathrm{m}^{18,19}$. Albrektsson \& Wennerberg ${ }^{18}$ suggested that smooth surfaces have an $\mathrm{S}_{\mathrm{a}}$ value of $<0.5 \mu \mathrm{m}$, minimally rough surfaces $0.5-1.0 \mu \mathrm{m}$, moderately rough surfaces $1.0-2.0 \mu \mathrm{m}$, and rough surfaces $>2.0 \mu \mathrm{m}$. Thus, the values found in the present study for the roughness parameter $S_{a}$ seems to be too high when a temperature of $120^{\circ} \mathrm{C}$ is applied, at least for the etching times of 15 and 30 minutes. As for the temperatures of 60 and $90^{\circ} \mathrm{C}$, it seems that a minimum of 15 minutes is required in order to obtain a surface that is classified as moderately rough. The results of the correlation and regression analyses showed that the temperature makes the strongest contribution in the variance of the mean values of the surface roughness parameters when compared to the etching time.

Although a good correlation between increased $\mathrm{R}_{\mathrm{a}}$ (bi-dimensional correlate of the three-dimensional $\mathrm{S}_{\mathrm{a}}$ ) and stronger anchorage ${ }^{5,17,20}$ was observed in the literature, one cannot speculate on their biological performance until their bone interlocking capacity is demonstrated. It turns out that clinical implications cannot be drawn by relying on roughness-descriptive parameters alone $e^{4}$. Moreover, $\mathrm{S}_{\mathrm{a}}\left(\mathrm{R}_{\mathrm{a}}\right)$ is insufficient by its own to characterize a given surface.

The increase in temperature changed the irregularity pattern from linear grooves with sharp edges to micro-pits and finally to deeper valleys, removing the grooves produced by the polishing process. The acid etching can create a surface with homogeneously distributed grooves and sharp edges at the micron-scale (at a temperature about $60{ }^{\circ} \mathrm{C}$ ), randomly create pits throughout the surface (at a temperature about $90^{\circ} \mathrm{C}$ ), or deep valleys and high ridges (at a temperature about $120^{\circ} \mathrm{C}$ ), enlarging the surface area. The surfaces kept the irregularity aspect when submitted to the same etching temperature. On the other hand, the irregularities increased in size and depth with increasing etching time. The problem with the $120^{\circ} \mathrm{C}$ samples with 15 and 30 minutes of etching time is that the etching process produced very large irregularities when the samples were seen by the naked eye, with a brittle surface in some regions, which peeled out when scratched.

Concerning the chemical evaluation, the EDS analysis of the surfaces showed oxygen and titanium to be the only elements in all groups. This is most probably due to the natural formation of a titanium oxide passivation layer just after sample surface preparation, mainly $\mathrm{TiO}_{2}$. The result agrees with the mass percentage of the $\mathrm{TiO}_{2}$ (about $60 \% / 40 \%$ ), which is the main component of a typical titanium oxide passivation layer.

Although the EDS analysis was able to detect the presence of $\mathrm{TiO}_{2}$, the same did not happen with the GIXRD analysis, probably due to the $\mathrm{TiO}_{2}$ ultrathin thickness, as it may happen in the case of the $\mathrm{TiO}_{2}$ itself $^{21}$ or for other compounds/phases ${ }^{22}$. However, GIXRD analysis demonstrated the presence of $\mathrm{TiH}_{2}$ on the surface of all samples submitted to acid etching. It was shown by XRD and metallographic microscopy analyses that the etching process modifies the $\mathrm{Ti}$ surface composition of sandblasted and acid-etched-treated implants indicating the presence of 20 to $40 \%$ of titanium hydride $\left(\mathrm{TiH}_{\mathrm{x}}, \mathrm{x} \leq 2\right)$ in addition to $\mathrm{Ti}^{23}$. It was suggested that titanium hydride may be biologically important because a hydride layer is much better suited as a template for binding biomolecules chemically onto a titanium surface ${ }^{24}$. In process of $\mathrm{TiH}_{2}$ formation, first the acids must dissolve the protective titanium oxide layer before attacking the metallic titanium. Then native hydrogen ions $\left(\mathrm{H}^{+}\right)$of the acid solution are released in the corrosion process of titanium. As the metal is left without its dense protective oxide layer, the small ions of hydrogen diffuse rapidly into the metal. The sub-surface is therefore enriched with hydrogen ${ }^{25}$, and when saturation in hydrogen is reached, titanium hydride is formed.

Although some of the surfaces here created using specific acid etching methods resemble chemically and topographically surfaces with osseointegration potential described in the literature, further research is necessary to clear up the influence of acid etching methods on the biological response. Moreover, since the present study has used discs as the substrate material, the observed results cannot be directly extrapolated to complex surfaces like those in cylindrical threaded titanium implants.

\section{Conclusions}

Titanium surface showed great variability when submitted to acid etching depending on the temperature and etching time. The surfaces kept the irregularity aspect when submitted to the same etching temperature. On the other hand, the irregularities increased in size and depth with increasing etching time. The mean value of $\mathrm{S}_{\mathrm{a}}$ increased with temperature and time. The temperature made the strongest contribution in the variance of the mean values of the surface roughness parameters when compared to the etching time. EDS analysis of the surfaces showed titanium and oxygen to be the only elements in all groups, and all test group samples showed the presence of titanium hydride on the surface, as observed by GIXRD analysis.

\section{Acknowledgements}

This work was supported by the Brazilian agencies $\mathrm{CNPq}$ and FAPEMIG. The authors would like to thank Eduardo Antônio de Carvalho (CDTN/CNEN). 


\section{References}

1. Albrektsson T, Brånemark PI, Hansson HA and Lindström J. Osseointegrated titanium implants. Requirements for ensuring a long-lasting, direct bone-to-implant anchorage in man. Acta Orthopaedica Scandinavica. 1981; 52(2):155-170. http://dx.doi. org/10.3109/17453678108991776. PMid:7246093.

2. Wennerberg A and Albrektsson T. Effects of titanium surface topography on bone integration: a systematic review. Clinical Oral Implants Research. 2009; 20(Suppl 4):172-184. http:// dx.doi.org/10.1111/j.1600-0501.2009.01775.x. PMid:19663964.

3. Wennerberg A and Albrektsson T. Structural influence from calcium phosphate coatings and its possible effect on enhanced bone integration. Acta Odontologica Scandinavica. 2009; 67(6):333-340. http://dx.doi.org/10.1080/00016350903188325. PMid:19722110.

4. Szmukler-Moncler S, Testori T and Bernard JP. Etched implants: a comparative surface analysis of four implant systems. Journal of Biomedical Materials Research. Part B, Applied Biomaterials. 2004; 69(1):46-57. http://dx.doi.org/10.1002/jbm.b.20021. PMid:15015209.

5. Klokkevold PR, Johnson P, Dadgostari S, Davies JE, Caputo A and Nishimura RD. Early endosseous integration enhanced by dual acid etching of titanium: a torque removal study in the rabbit. Clinical Oral Implants Research. 2001; 12(4):350-357. http://dx.doi.org/10.1034/j.1600-0501.2001.012004350.x. PMid:11488864.

6. Daugaard H, Elmengaard B, Bechtold JE and Soballe K. Bone growth enhancement in vivo on press-fit titanium alloy implants with acid etched microtexture. Journal of Biomedical Materials Research. Part A. 2008; 87(2):434-440. http://dx.doi. org/10.1002/jbm.a.31748. PMid:18186059.

7. Chrcanovic BR, Leão NLC and Martins MD. Influence of different acid etchings on the superficial characteristics of $\mathrm{Ti}$ sandblasted with A12O3. Materials Research. 2013; 16(5):10061014. http://dx.doi.org/10.1590/S1516-14392013005000067.

8. Chrcanovic BR and Martins MD. Study of the influence of acid etching treatments on the superficial characteristics of Ti. Materials Research. 2014; 17(2):373-380. http://dx.doi. org/10.1590/S1516-14392014005000042.

9. Lazzara RJ, Testori T, Trisi P, Porter SS and Weinstein RL. A human histologic analysis of osseotite and machined surfaces using implants with 2 opposing surfaces. The International Journal of Periodontics \& Restorative Dentistry. 1999; 19(2):117-129. PMid:10635177.

10. He FM, Yang GL, Zhao SF and Cheng ZP. Mechanical and histomorphometric evaluations of rough titanium implants treated with hydrofluoric acid/nitric acid solution in rabbit tibia. The International Journal of Oral \& Maxillofacial Implants. 2011; 26(1):115-122. PMid:21365046.

11. Zareidoost A, Yousefpour M, Ghaseme B and Amanzadeh A. The relationship of surface roughness and cell response of chemical surface modification of titanium. Journal of Materials Science. Materials in Medicine. 2012; 23(6):1479-1488. http:// dx.doi.org/10.1007/s10856-012-4611-9. PMid:22460230.

12. Albrektsson $T$ and Wennerberg A. Oral implant surfaces: Part 2--review focusing on clinical knowledge of different surfaces. The International Journal of Prosthodontics. 2004; 17(5):544564. PMid:15543911.

13. Wennerberg A and Albrektsson T. Suggested guidelines for the topographic evaluation of implant surfaces. The International
Journal of Oral \& Maxillofacial Implants. 2000; 15(3):331344. PMid:10874798.

14. Stout KJ, editor. Development of the methods for the characterisation of roughness in three dimensions. Luxembourg: Penton Press; 1993.

15. Chrcanovic BR, Pedrosa AR and Martins MD. Chemical and topographic analysis of treated surfaces of five different commercial dental titanium implants. Materials Research. 2012; 15(3):372382. http://dx.doi.org/10.1590/S1516-14392012005000035.

16. Souza FA, Queiroz TP, Guastaldi AC, Garcia-Júnior IR, MagroFilho O, Nishioka RS, et al. Comparative in vivo study of commercially pure Ti implants with surfaces modified by laser with and without silicate deposition: biomechanical and scanning electron microscopy analysis. Journal of Biomedical Materials Research. Part B, Applied Biomaterials. 2013; 101(1):76-84. http://dx.doi.org/10.1002/jbm.b.32818. PMid:23090936.

17. Wong M, Eulenberger J, Schenk R and Hunziker E. Effect of surface topology on the osseointegration of implant materials in trabecular bone. Journal of Biomedical Materials Research. 1995; 29(12):1567-1575. http://dx.doi.org/10.1002/jbm.820291213. PMid:8600147.

18. Albrektsson T and Wennerberg A. Oral implant surfaces. Part 1: review focusing on topographic and chemical properties of different surfaces and in vivo responses to them. The International Journal of Prosthodontics. 2004; 17(5):536-543. PMid: 15543910.

19. Buser D, Broggini N, Wieland M, Schenk RK, Denzer AJ, Cochran DL, et al. Enhanced bone apposition to a chemically modified SLA titanium surface. Journal of Dental Research. 2004; 83(7):529-533. http://dx.doi.org/10.1177/154405910408300704. PMid:15218041.

20. Gotfredsen K, Berglundh T and Lindhe J. Anchorage of titanium implants with different surface characteristics: an experimental study in rabbits. Clinical Implant Dentistry and Related Research. 2000; 2(3):120-128. http://dx.doi.org/10.1111/j.1708-8208.2000. tb00002.x. PMid:11359256.

21. Han GS, Chung HS, Kim BJ, Kim DH, Lee JW, Swain BS, et al. Retarding charge recombination in perovskite solar cells using ultrathin $\mathrm{MgO}$-coated $\mathrm{TiO} 2$ nanoparticulate films. Journal of Materials Chemistry. A, Materials for Energy and Sustainability. 2015; 3(17):9160-9164. http://dx.doi.org/10.1039/C4TA03684K.

22. Teng-amnuay N, Tangpatjaroen C, Nisaratanaporn E and Lohwongwatana B. Replication of trabecular bone structure and reaction layer analysis of titanium alloys using investment casting technique. Procedia Technology. 2014; 12:316-322. http://dx.doi.org/10.1016/j.protcy.2013.12.492.

23. Perrin D, Szmukler-Moncler S, Echikou C, Pointaire P and Bernard JP. Bone response to alteration of surface topography and surface composition of sandblasted and acid etched (SLA) implants. Clinical Oral Implants Research. 2002; 13(5):465469. http://dx.doi.org/10.1034/j.1600-0501.2002.130504.x. PMid:12453122.

24. Videm K, Lamolle S, Monjo M, Ellingsen JE, Lyngstadaas SP and Haugen HJ. Hydride formation on titanium surfaces by cathodic polarization. Applied Surface Science. 2008; 255(5):3011-3015. http://dx.doi.org/10.1016/j.apsusc.2008.08.090.

25. Frank MJ, Walter MS, Lyngstadaas SP, Wintermantel E and Haugen HJ. Hydrogen content in titanium and a titanium-zirconium alloy after acid etching. Materials Science and Engineering C. 2013; 33(3):1282-1288. http://dx.doi.org/10.1016/j.msec.2012.12.027. PMid:23827573. 